\title{
Traffic-related air pollution and respiratory health during the first 2 yrs of life
}

\author{
U. Gehring*\#, J. Cyrys*, G. Sedlmeir ${ }^{\star}$, B. Brunekreef ${ }^{+}$, T. Bellander ${ }^{\S}$, P. Fischer ${ }^{f}$, C.P. Bauer**, \\ D. Reinhardt"\#, H.E. Wichmann*\#, J. Heinrich*
}

Traffic-related air pollution and respiratory health during the first 2 yrs of life. U. Gehring, J. Cyrys, G. Sedlmeir, B. Brunekreef, T. Bellander, P. Fischer, C.P. Bauer, D. Reinhardt, H.E. Wichmann, J. Heinrich. (C) ERS Journals Ltd 2002.

ABSTRACT: As part of an international collaborative study on the impact of TrafficRelated Air Pollution on Childhood Asthma (TRAPCA), the health effects associated with long-term exposure to particles with a $50 \%$ cut-off aerodynamic diameter of $2.5 \mu \mathrm{m}$ (PM2.5), PM2.5 absorbance, and nitrogen dioxide $\left(\mathrm{NO}_{2}\right)$ were analysed.

The German part of the TRAPCA study used data from subpopulations of two ongoing birth cohort studies (German Infant Nutrition Intervention Programme (GINI) and Influences of Lifestyle Related Factors on the Human Immune System and Development of Allergies in Children (LISA)) based in the city of Munich. Geographic information systems (GIS)-based exposure modelling was used to estimate trafficrelated air pollutants at the birth addresses of 1,756 infants. Logistic regression was used to analyse possible health effects and potential confounding factors were adjusted for.

The ranges in estimated exposures to $\mathrm{PM} 2.5, \mathrm{PM} 2.5$ absorbance, and $\mathrm{NO}_{2}$ were 11.9-21.9 $\mu \mathrm{g} \cdot \mathrm{m}^{-3}, 1.38-4.39 \times 10^{-5} \mathrm{~m}^{-1}$, and $19.5-66.9 \mu \mathrm{g} \cdot \mathrm{m}^{3}$, respectively. Significant associations between these pollutants and cough without infection (odds ratio (OR) (95\% confidence interval (CI)): $1.34(1.11-1.61), 1.32(1.10-1.59)$, and 1.40 (1.12-1.75), respectively) and dry cough at night (OR $(95 \% \mathrm{CI})$ : $1.31(1.07-1.60)$, $1.27(1.04-1.55)$, and $1.36(1.07-1.74)$, respectively) in the first year of life were found. In the second year of life, these effects were attenuated.

There was some indication of an association between traffic-related air pollution and symptoms of cough. Due to the very young age of the infants, it was too early to draw definitive conclusions from this for the development of asthma.

Eur Respir J 2002; 19: 690-698.
*GSF-National Research Centre for Environment and Health, Institute of Epidemiology, Neuherberg and ${ }^{\#}$ Chair of Epidemiology, Ludwig-MaximiliansUniversity of Munich and City of Munich, Dept of Environment and Health, Munich, Germany. ${ }^{+}$Environmental and Occupational Health Group, Institute for Risk Assessment Sciences, Utrecht University, Utrecht, the Netherlands. ${ }^{\S}$ Institute of Environmental Medicine, Karolinska Institute, Stockholm, Sweden. ${ }^{f}$ RIVM-National Institute of Public Health and Environment, Bilthoven, the Netherlands. **Dept of Paediatrics, Technical University of Munich and ${ }^{\# \#}$ Dept of Pediatrics, Ludwig-Maximilians-University of Munich, Munich, Germany.

Correspondence: U. Gehring, GSFNational Research Centre for Environment and Health, Institute of Epidemiology, Ingolstaedter Landstr. 1, D-85764 Neuherberg, Germany. Fax: 498931873380 E-mail: gehring@gsf.de

Keywords: Air pollution, geographic information systems, infants, respiratory symptoms, traffic

Received: August 12001

Accepted after revision November 22 2001

This study was supported by the EU grant ENV4 CT97-0506.
Motor traffic is a major source of air pollutants such as nitrogen dioxide $\left(\mathrm{NO}_{2}\right)$ and suspended particulate matter. Recent research has focused on the impact of traffic-related air pollution on morbidity and mortality [1]. Whereas most epidemiological studies deal with short-term effects, only a few studies have reported long-term effects [2]. Therefore, there is a need for more studies assessing the long-term effects of outdoor air pollution.

In recent years, several studies have indicated that exposure to $\mathrm{NO}_{2}$ [3-5], and particulate matter [6], proximity of homes to roadsides [7] and motorways [8] as well as exposure to high rates of road traffic [9] and in particular to truck traffic $[8,10-13]$ increases the risk of respiratory symptoms. The associations between traffic-related air pollution and asthma and lung function are less clear. A positive association between hospital admission for asthma and traffic density among children was reported by one casecontrol study [14], whereas another case-control study failed to show such an association [15]. In two studies lung function was found to be decreased with increasing traffic density [8], whereas no associations with pulmonary function measures were found in others $[9,16]$.

A major deficiency in many of these studies involves the estimation of exposure. Proximity to road traffic $[3,7,8,15]$, census data on car traffic and/or truck traffic $[8,9,14,17]$, and self-reported traffic intensities [10-13] were used as proxies for exposure to traffic 
exhaust. One study used modelled $\mathrm{NO}_{2}$ concentrations [3]. Only a few studies relied on exposure measurements $[8,17,18]$. Since it is not feasible to measure personal exposure for large study populations, exposure modelling based on either pollution dispersion models or measurement data seems to be a useful approach. BRIGGS and co-workers [19, 20] presented a regression-based approach for mapping long-term exposure to $\mathrm{NO}_{2}$ using Geographic information systems (GIS), which can be easily applied to large study populations.

As part of an international collaborative study on the impact of Traffic-Related Air Pollution on Childhood Asthma (TRAPCA), the health effects associated with long-term exposure to $\mathrm{NO}_{2}$, particles with a 50\% cut-off aerodynamic diameter of $2.5 \mu \mathrm{m}$ (PM2.5) and PM2.5 absorbance in Sweden, the Netherlands, and Germany were analysed. The results of the German part of the TRAPCA study using data for the first 2 yrs of life from two ongoing birth cohort studies (German Infant Nutrition Intervention Programme (GINI) and Influences of Lifestyle Related Factors on the Immune System and Development of Allergies in Children (LISA)) carried out in the city of Munich are described. A GIS-based exposure modelling similar to that used by BRIGGS and co-workers $[19,20]$ was used.

\section{Materials and methods}

\section{Study area}

The study was conducted in the city of Munich, the capital of Bavaria, situated in the South of Germany. In 1999 Munich had a population of $\sim 1.32$ million inhabitants in an area of $3,104,400 \mathrm{~m}^{2}$ and there were 703,231 cars registered [21].

\section{Study population}

The German part of the TRAPCA study used data from two ongoing birth cohorts, GINI and LISA. There was no overlap between the two studies, as the children were either participants of the GINI study or participants of the LISA study, but not of both studies.

For the GINI cohort, parents who attended one of 16 maternity hospitals in the two study regions of Munich and Wesel were invited to participate in the study. From September 1995-June 1998, a total of 5,991 healthy, term newborns, whose parents had a sufficient knowledge of the German language, were recruited. A subgroup of 2,252 infants with at least one atopic parent or sibling took part in the intervention program (GINI intervention study) and were randomly assigned to one of four study formulas. The remaining infants took part in the GINI observation study. Both the intervention and observation studies, are referred to as GINI study in the remainder of this paper.

The participants of the LISA study were recruited from the two large German cities, Munich and
Leipzig. Parents were recruited during pregnancy. From December 1997-January 1999, newborns from parents who were born in Germany and had German nationality from six obstetrical clinics in Munich and four obstetrical clinics in Leipzig were defined as the target population for the study. Neonates fulfilling at least one of the following criteria were excluded from the study: premature birth (maturity $<37$ gestational weeks), low birth weight $(<2,500 \mathrm{~g})$, congenital malformation, symptomatic neonatal infection, antibiotic medication, hospitalization or intensive medical care during neonatal period, immune-related diseases of the mother (autoimmune disorders, diabetes, hepatitis B), long-term medication or abuse of drugs and alcohol. The final study population consisted of 2,443 neonates.

For the TRAPCA cohort, all infants with birth addresses in Munich (without surrounding communities, postal code 80000-81999), of whom questionnaire data was available for the first year of life, and who did not move away from Munich within the first year of life (fig. 1) were selected. A total of 1,757 infants, 1,084 form the GINI cohort and 673 from the LISA cohort, fulfilled these criteria. For one infant, no GIS data was available. Thus, the final cohort consisted of 1,756 infants.

The studies were approved by the medical association of the state of Bavaria (Landesaerztekammer Bavaria) and were carried out in accordance with the institutional guidelines for the protection of human subjects. Informed consent was obtained from all parents of the participating children.

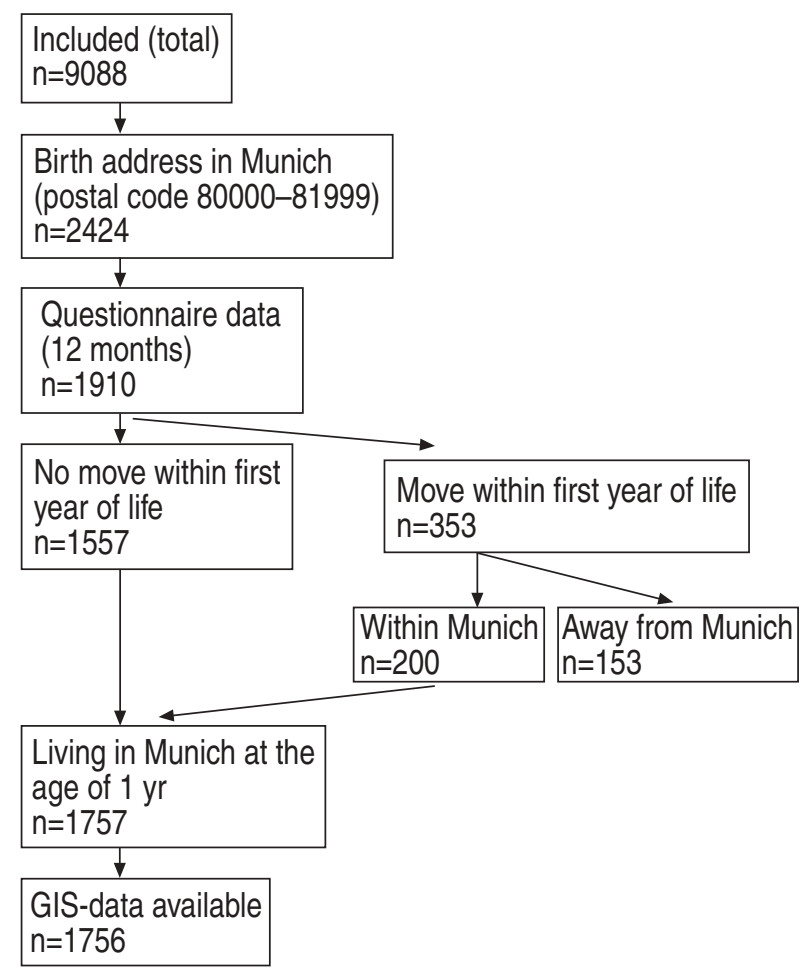

Fig. 1.-Description of the study population. 


\section{Respiratory symptoms}

Respiratory symptoms were assessed by parental completed questionnaires. Parents of the GINI cohort received a questionnaire at birth, and then every 12 months; parents of the LISA cohort received a questionnaire at birth, and then every 6 months. Data derived from these questionnaires was used for the definition of the primary outcomes. The questionnaire requested information regarding wheezing, symptoms of cough, sneezing, running and/or stuffed nose without a cold, bronchial asthma, bronchitis, and respiratory infections. The wording of the questions used for the definition of these outcome variables was identical in the two cohorts.

\section{Confounding variables}

Information on potential confounding variables was also assessed by parental completed questionnaires. Data from these questionnaires included information on sex, parental history of atopy (asthma and/or hayfever and/or eczema), parental education, siblings, environmental tobacco smoke (ETS) at home, use of gas, home dampness, visible indoor moulds, and the keeping of pets.

\section{Estimation of ambient air pollution exposure for the cohort}

Since it is not feasible to measure personal exposure to air pollution $\left(\mathrm{NO}_{2}, \mathrm{PM} 2.5\right.$, and PM2.5 absorbance) for all study subjects, exposure modelling was used. PM2.5 absorbance was used as a marker for diesel "soot" in order to distinguish potential health effects of emissions from all motorized vehicles from those of heavy vehicles only. Regression models were developed based upon measurements and simple predictor variables from a GIS that was available for the measurement sites and for each subject. In total, 40 measurement sites were selected. These sites were divided among urban background and street sites. To capture all of the variation in air pollution concentrations that might be experienced by the study subjects, street sites that were located both at main roads and at side roads were selected. The background sites were spread over the whole city from the inner city to the suburb.

At each site, four 14-day measurements were conducted, such that each site was measured in each season once. For PM2.5 sampling the Harvard impactor (Air diagnostics Inc., Naples, Maine, USA) [22] was operated according to a standard operating procedure. Following sample collection, the same PM2.5 filters were transported to laboratories for weighing and reflectance measurements. PM2.5 absorbance (the reflectance of the filters) was measured according to procedures described previously [23]. $\mathrm{NO}_{2}$ was measured with Palmes tubes, according to a standardized operating procedure [24]. For all pollutants annual averages were calculated. In brief, measurements at the 40 sites were not performed simultaneously. Therefore differences among the sites may have occurred due to temporal variation. As the measurements were intended to incorporate spatial variability only, the annual averages were adjusted for the impact of temporal variability using data from one site where continuous measurements were made over the entire study period.

The annual average concentrations were related to a set of predictor variables obtained from a GIS, using regression modelling. The following GIS variables were collected using GIS ARC VIEW version 3.2. (ESRI, Redlands, CA, USA): traffic density, heavy vehicle intensity, household density, population density. All these variables were determined for three different circular buffers around the sites. A detailed description of the GIS variables and the regression models will be provided in separate papers. In brief, a substantial fraction of the variability in annual concentrations at the measurement sites could be explained by the GIS variables. A larger percentage of the absorbance of $\mathrm{PM} 2.5$ and $\mathrm{NO}_{2}$ was explained than for PM2.5. The most influential variables were traffic intensities in the 50 and $250 \mathrm{~m}$ buffers and address density in the $300 \mathrm{~m}$ buffer (for $\mathrm{NO}_{2}$ ). The percentage of variability explained by the model $\left(\mathrm{R}^{2}\right)$ was 0.56 , 0.67 , and 0.62 for PM2.5, PM2.5 absorbance, and $\mathrm{NO}_{2}$, respectively.

For 1,756 study subjects birth addresses could be converted into geographical coordinates. Using these coordinates the values for all the potential predictors were obtained for all study subjects. A quantitative estimate of air pollution exposure was obtained for each child by means of the regression model.

\section{Statistical methods}

Multiple logistic regression analyses were performed to analyse the relationship between respiratory symptoms and disease on the one hand and estimated air pollution exposure on the other hand. Potential confounding factors such as sex, parental atopy, maternal education, siblings, ETS at home, use of gas for cooking, home dampness, indoor moulds, and keeping of dogs and cats were adjusted for. Concentrations of PM2.5, PM2.5 absorbance, and $\mathrm{NO}_{2}$ were all divided by their respective interquartile ranges, in order to create exposure variables that would yield mutually comparable coefficients in the statistical analyses. Results are presented as adjusted odds ratios (OR) with 95\% confidence intervals (CI). Statistical significance was defined by a two-sided alpha level of $5 \%$.

\section{Results}

\section{Description of the study population}

A description of the study population is given in table 1. Lifetime prevalence of the selected outcomes are given for the age of 1 and $2 \mathrm{yrs}$, respectively. 
Table 1.-Description of the study cohort

\begin{tabular}{|c|c|c|}
\hline & \multicolumn{2}{|c|}{ Frequency } \\
\hline & $\mathrm{n} / \mathrm{N}$ & Prevalence $\%$ \\
\hline \multicolumn{3}{|l|}{ Variable } \\
\hline \multicolumn{3}{|l|}{ Age of $1 \mathrm{yr}$} \\
\hline Wheezing & $258 / 1722$ & 15.0 \\
\hline Cough w/o infection & $151 / 1655$ & 9.1 \\
\hline Dry cough at night & $123 / 1737$ & 7.1 \\
\hline $\begin{array}{l}\text { Doctor diagnosed } \\
\text { bronchial asthma }\end{array}$ & $6 / 1731$ & 0.4 \\
\hline $\begin{array}{l}\text { Doctor diagnosed asthmoid/ } \\
\text { spast./obstr. bronchitis }\end{array}$ & $196 / 1735$ & 11.3 \\
\hline $\begin{array}{l}\text { Doctor diagnosed } \\
\text { respiratory infections }\end{array}$ & $1212 / 1728$ & 70.1 \\
\hline $\begin{array}{l}\text { Sneezing, running/stuffed } \\
\text { nose w/o a cold }\end{array}$ & $254 / 1743$ & 14.6 \\
\hline \multicolumn{3}{|l|}{ Age of $2 \mathrm{yrs}^{\#}$} \\
\hline Wheezing & $416 / 1627$ & 25.6 \\
\hline Dry cough at night & $228 / 1614$ & 14.1 \\
\hline $\begin{array}{l}\text { Doctor diagnosed } \\
\text { bronchial asthma }\end{array}$ & $16 / 1600$ & 1.0 \\
\hline $\begin{array}{l}\text { Doctor diagnosed asthmoid/ } \\
\text { spast./obstr. bronchitis }\end{array}$ & $303 / 1616$ & 8.8 \\
\hline $\begin{array}{l}\text { Doctor diagnosed } \\
\text { respiratory infections }\end{array}$ & $1528 / 1695$ & 90.2 \\
\hline $\begin{array}{l}\text { Sneezing, running/stuffed } \\
\text { nose w/o a cold }\end{array}$ & $354 / 1638$ & 21.6 \\
\hline \multicolumn{3}{|l|}{ Confounding variables } \\
\hline Female sex & $832 / 1756$ & 47.4 \\
\hline Parental atopy & $935 / 1756$ & 53.3 \\
\hline ETS at home & $398 / 1704$ & 23.4 \\
\hline \multicolumn{3}{|l|}{ Maternal education } \\
\hline$<12$ grades & $633 / 1751$ & 36.1 \\
\hline$\geqslant 12$ grades & $1118 / 1751$ & 63.9 \\
\hline Siblings & $700 / 1712$ & 40.9 \\
\hline Use of gas for cooking & $221 / 1731$ & 12.8 \\
\hline Home dampness & $115 / 1731$ & 6.6 \\
\hline Indoor moulds & $534 / 1735$ & 30.8 \\
\hline Keeping of pets & $318 / 1739$ & 18.3 \\
\hline Cat & $159 / 1735$ & 9.2 \\
\hline Dog & $70 / 1735$ & 4.0 \\
\hline
\end{tabular}

$\mathrm{n} / \mathrm{N}$ : number of subjects/total number of subjects; ETS: environmental tobacco smoke; obstr.: obstructive; spast.: spastic; w/o: without. " : lifetime prevalence.

All prevalence, except the prevalence of asthma, were sufficiently high to analyse the association with exposure to air pollution. Data on cough without a cold was available for the first year of life only. Pets were kept in $18 \%$ of homes and cats were more common than dogs. More than $50 \%$ of children had a positive parental history of atopy. Maternal education was high $(64 \%$ of mothers had $\geqslant 12$ grades).

\section{Exposure to ambient air pollutants}

The distribution of the estimated exposures to PM2.5, PM2.5 absorbance, and $\mathrm{NO}_{2}$ are presented in table 2. There is a substantial variability in exposure to all three pollutants. Estimated exposures to PM2.5, PM2.5 absorbance, and $\mathrm{NO}_{2}$ ranged from 11.9$21.9 \mu \mathrm{g} \cdot \mathrm{m}^{3}$, from $1.38-4.39 \times 10^{-5} \mathrm{~m}^{-1}$, and from $19.5-66.9 \mu \mathrm{g} \cdot \mathrm{m}^{3}$, respectively. The range in exposure
Table 2. - Distribution of estimated annual averages in the cohort

\begin{tabular}{lccc}
\hline & $\begin{array}{c}\mathrm{PM} 2.5 \\
\mu \mathrm{g} \cdot \mathrm{m}^{-3}\end{array}$ & $\begin{array}{c}\mathrm{PM} 2.5 \text { absorbance } \\
10^{-5} \mathrm{~m}^{-1}\end{array}$ & $\begin{array}{c}\mathrm{NO}_{2} \\
\mu \mathrm{g} \cdot \mathrm{m}^{-3}\end{array}$ \\
\hline Minimum & 11.9 & 1.38 & 19.5 \\
10th percentile & 12.2 & 1.47 & 21.6 \\
25th percentile & 12.5 & 1.54 & 23.0 \\
50th percentile & 13.1 & 1.70 & 26.4 \\
Mean & 13.4 & 1.77 & 27.8 \\
75th percentile & 14.0 & 1.88 & 31.5 \\
90th percentile & 14.9 & 2.13 & 35.2 \\
Maximum & 21.9 & 4.39 & 66.9 \\
\hline
\end{tabular}

PM2.5: particles with a cut-off aerodynamic diameter of $2.5 \mu \mathrm{m} ; \mathrm{NO}_{2}$ : nitrogen dioxide.

was smallest for PM2.5, where the difference between the 10th and 90th percentile was relatively small $\left(12.2-14.9 \mu \mathrm{g} \cdot \mathrm{m}^{-3}\right)$. The exposure estimates for the different pollutants were very highly correlated. The correlations of PM2.5 with PM2.5 absorbance and $\mathrm{NO}_{2}$ were 0.96 and 0.99 respectively; the correlation of PM2.5 absorbance and $\mathrm{NO}_{2}$ was 0.95 .

\section{Relationship between ambient air pollutant exposure and symptoms}

Results of the multiple logistic regression analyses are presented in table 3. The associations between PM2.5, PM2.5 absorbance, and $\mathrm{NO}_{2}$ on the one hand and cough without infection (OR (95\% CI): 1.34 (1.11-1.61), 1.32 (1.10-1.59), and 1.40 (1.12-1.75), respectively) and dry cough at night in the first year of life (OR (95\% CI): 1.31 (1.07-1.60), 1.27 (1.04-1.55), and $1.36(1.07-1.74)$, respectively) on the other hand were found to be statistically significant. The effects on dry cough at night were attenuated for the second year of life. All other ORs were close to unity. Results of the multiple logistic regression analysis stratified for sex showed stronger effects in males compared to females (tables 4 and 5).

In addition, multiple logistic regression analyses stratified for parental atopy were conducted. The effects on dry cough at night were found to be somewhat higher in the group of children without parental atopy compared to children with parental atopy (data not shown). But differences between children with and without parental atopy were less pronounced than differences between males and females.

\section{Discussion}

In this study, reports of cough without infection and dry cough at night in the first year of life were found to be associated with exposure to traffic-related air pollution. The associations were attenuated for the second year of life. Stratified analyses showed stronger associations for males compared to females.

Exposure to traffic-related air pollution was assessed in a more sophisticated way than in many 
Table 3. - Multiple logistic regression analysis of associations between symptoms in the first and second year of life and exposure to traffic-related air pollution

\begin{tabular}{|c|c|c|c|c|c|c|}
\hline \multirow{2}{*}{$\begin{array}{l}\text { Exposure } \\
\text { variable }\end{array}$} & \multicolumn{6}{|c|}{ Symptom variable } \\
\hline & Wheeze & $\begin{array}{l}\text { Cough without } \\
\text { infection }\end{array}$ & $\begin{array}{l}\text { Dry cough } \\
\text { at night }\end{array}$ & $\begin{array}{l}\text { Obstr./spast./ } \\
\text { asthmoid } \\
\text { bronchitis }\end{array}$ & $\begin{array}{l}\text { Respiratory } \\
\text { infections }\end{array}$ & $\begin{array}{l}\text { Sneezing, } \\
\text { runnyl } \\
\text { stuffed nose }\end{array}$ \\
\hline \multicolumn{7}{|l|}{ Age of $1 \mathrm{yr}$} \\
\hline Subjects $\mathrm{n}$ & 1597 & 1528 & 1607 & 1606 & 1600 & 1614 \\
\hline $\mathrm{PM}_{2.5}$ & $0.91(0.76-1.09)$ & $1.34(1.11-1.61)$ & $1.31(1.07-1.60)$ & $0.98(0.80-1.20)$ & $1.04(0.91-1.19)$ & $1.01(0.85-1.20)$ \\
\hline PM2.5 abs & $0.93(0.78-1.12)$ & $1.32(1.10-1.59)$ & $1.27(1.04-1.55)$ & $0.99(0.81-1.22)$ & $1.03(0.90-1.18)$ & $0.95(0.79-1.14)$ \\
\hline $\mathrm{NO}_{2}$ & $0.87(0.70-1.08)$ & $1.40(1.12-1.75)$ & $1.36(1.07-1.74)$ & $0.97(0.77-1.23)$ & $1.06(0.91-1.24)$ & $0.99(0.81-1.22)$ \\
\hline \multicolumn{7}{|l|}{ Age of 2 yrs } \\
\hline Subjects $n$ & 1517 & & 1507 & 1510 & 1577 & 1523 \\
\hline $\mathrm{PM}_{2.5}$ & $0.96(0.83-1.12)$ & NA & $1.20(1.02-1.42)$ & $0.92(0.78-1.09)$ & $0.98(0.80-1.20)$ & $0.96(0.82-1.12)$ \\
\hline PM2.5 abs & $0.98(0.84-1.14)$ & NA & $1.16(0.98-1.37)$ & $0.94(0.79-1.12)$ & $0.99(0.80-1.22)$ & $0.92(0.78-1.09)$ \\
\hline $\mathrm{NO}_{2}$ & $0.94(0.79-1.12)$ & NA & $1.24(1.02-1.51)$ & $0.90(0.74-1.10)$ & $0.98(0.78-1.25)$ & $0.93(0.78-1.12)$ \\
\hline
\end{tabular}

Data are presented as ${ }^{\#}$ adjusted odds ratio of symptoms $(95 \%$ confidence interval) associated with a change in concentration of $1.5 \mu \mathrm{g} \cdot \mathrm{m}^{-3}$ for PM2.5, $0.4 \times 10^{-5} \cdot \mathrm{m}^{-1}$ for PM2.5 abs and $8.5 \mu \mathrm{g} \cdot \mathrm{m}^{-3}$ for $\mathrm{NO}_{2}$. PM 2.5 : particles with a $50 \%$ aerodynamic cut-off diameter of $2.5 \mu \mathrm{m} ; \mathrm{NO}_{2}$ : nitrogen dioxide; obstr.: obstructive; spast.: spastic; NA: not available. ${ }^{\#}$ : Adjusted for sex, parental atopy (yes/no), maternal education, siblings $(y / n)$, environmental tobacco smoke at home $(y / n)$, use of gas for cooking (y/n), home dampness $(\mathrm{y} / \mathrm{n})$, indoor moulds $(\mathrm{y} / \mathrm{n})$, keeping of dogs $(\mathrm{y} / \mathrm{n})$ and cats $(\mathrm{y} / \mathrm{n})$ study (German Infant Nutrition Intervention Programme (GINI)-intervention, GINI-observation, Lifestyle Related Factors on the Human Immune System and Development of Allergies in children (LISA)).

other studies relying on proximity to road traffic $[3,7$, $8,15]$, census data on car traffic and/or truck traffic $[8,9,14,17]$, and self-reported traffic intensities [10-13] as proxies for exposure to traffic exhaust. These results show that the variance of measured, traffic-related air pollutants could be readily explained by a small number of variables present in available GIS databases [24]. It has been shown that the incorporation of additional variables besides distance to roadsides and immediate traffic intensity provided further additional explanatory power.
In the present study, rather unspecific respiratory symptoms were found to be associated with estimated exposure to traffic-related air pollution. No other cohort studies on the association between exposure to traffic-related air pollutants and respiratory health in infancy have been published to date. Most studies on the effects of traffic-related air pollution on asthma in children are cross-sectional studies dealing with school children. These studies have suggested that exposure to air pollution is associated with increased reporting of respiratory and allergic symptoms and illnesses

Table 4.-Multiple logistic regression analysis of associations between symptoms in the first and second year of life and exposure to traffic-related air pollution in males

\begin{tabular}{|c|c|c|c|c|c|c|}
\hline \multirow{2}{*}{$\begin{array}{l}\text { Exposure } \\
\text { variable }\end{array}$} & \multicolumn{6}{|c|}{ Symptom variable } \\
\hline & Wheeze & $\begin{array}{l}\text { Cough without } \\
\text { infection }\end{array}$ & $\begin{array}{l}\text { Dry cough } \\
\text { at night }\end{array}$ & $\begin{array}{l}\text { Obstr./spast./ } \\
\text { asthmoid } \\
\text { bronchitis }\end{array}$ & $\begin{array}{l}\text { Respiratory } \\
\text { infections }\end{array}$ & $\begin{array}{l}\text { Sneezing, } \\
\text { runny/ } \\
\text { stuffed nose }\end{array}$ \\
\hline \multicolumn{7}{|l|}{ Age of $1 \mathrm{yr}$} \\
\hline Subjects n & 844 & 811 & 50 & 845 & 846 & 853 \\
\hline PM2.5 & $0.91(0.72-1.16)$ & $1.43(1.14-1.80)$ & $1.39(1.08-1.78)$ & $0.97(0.76-1.25)$ & $1.04(0.87-1.25)$ & $0.97(0.77-1.24)$ \\
\hline $\mathrm{PM}_{2.5} \mathrm{abs}$ & $0.91(0.71-1.15)$ & $1.38(1.11-1.71)$ & $1.31(1.04-1.67)$ & $1.00(0.78-1.27)$ & $1.03(0.86-1.23)$ & $0.90(0.70-1.16)$ \\
\hline $\mathrm{NO}_{2}$ & $0.86(0.65-1.14)$ & $1.52(1.16-2.00)$ & $1.45(1.07-1.98)$ & $0.96(0.72-1.28)$ & $1.05(0.85-1.31)$ & $0.94(0.71-1.25)$ \\
\hline \multicolumn{7}{|l|}{ Age of $2 \mathrm{yrs}$} \\
\hline Subjects n & 801 & & 797 & 791 & 832 & 801 \\
\hline $\mathrm{PM} 2.5$ & $0.93(0.76-1.14)$ & NA & $1.25(1.01-1.55)$ & $0.92(0.74-1.14)$ & $0.99(0.74-1.31)$ & $0.91(0.73-1.12)$ \\
\hline $\mathrm{PM}_{2.5} \mathrm{abs}$ & $0.92(0.75-1.13)$ & NA & $1.17(0.95-1.44)$ & $0.91(0.72-1.13)$ & $0.96(0.73-1.26)$ & $0.83(0.66-1.05)$ \\
\hline $\mathrm{NO}_{2}$ & $0.88(0.69-1.12)$ & NA & $1.28(0.99-1.66)$ & $0.89(0.69-1.14)$ & $0.99(0.71-1.37)$ & $0.86(0.66-1.11)$ \\
\hline
\end{tabular}


Table 5.-Multiple logistic regression analysis of associations between symptoms in the first and second year of life and exposure to traffic-related air pollution in females

\begin{tabular}{|c|c|c|c|c|c|c|}
\hline \multirow{2}{*}{$\begin{array}{l}\text { Exposure } \\
\text { variable }\end{array}$} & \multicolumn{6}{|c|}{ Symptom variable } \\
\hline & Wheeze & $\begin{array}{l}\text { Cough without } \\
\text { infection }\end{array}$ & $\begin{array}{l}\text { Dry cough } \\
\text { at night }\end{array}$ & $\begin{array}{l}\text { Obstr./spast./ } \\
\text { asthmoid } \\
\text { bronchitis }\end{array}$ & $\begin{array}{l}\text { Respiratory } \\
\text { infections }\end{array}$ & $\begin{array}{l}\text { Sneezing, } \\
\text { runny/ } \\
\text { stuffed nose }\end{array}$ \\
\hline \multicolumn{7}{|l|}{ Age of $1 \mathrm{yr}$} \\
\hline Subjects n & 753 & 717 & 757 & 761 & 754 & 63 \\
\hline $\mathrm{PM} 2.5$ & $0.94(0.70-1.27)$ & $1.19(0.84-1.70)$ & $1.17(0.81-1.68)$ & $0.98(0.68-1.41)$ & $1.06(0.87-1.31)$ & $1.08(0.84-1.41)$ \\
\hline $\mathrm{PM} 2.5 \mathrm{abs}$ & $1.01(0.74-1.37)$ & $1.25(0.87-1.78)$ & $1.16(0.79-1.71)$ & $0.94(0.63-1.39)$ & $1.05(0.85-1.30)$ & $1.06(0.80-1.39)$ \\
\hline $\mathrm{NO}_{2}$ & $0.90(0.64-1.28)$ & $1.22(0.81-1.85)$ & $1.20(0.78-1.84)$ & $0.97(0.63-1.48)$ & $1.09(0.86-1.38)$ & $1.09(0.80-1.47)$ \\
\hline \multicolumn{7}{|l|}{ Age of 2 yrs } \\
\hline Subjects n & 716 & & 710 & 719 & 745 & 722 \\
\hline $\mathrm{PM} 2.5$ & $1.04(0.83-1.30)$ & NA & $1.13(0.86-1.48)$ & $0.91(0.68-1.21)$ & $0.98(0.73-1.31)$ & $1.04(0.83-1.31)$ \\
\hline $\mathrm{PM} 2.5 \mathrm{abs}$ & $1.07(0.85-1.36)$ & NA & $1.12(0.84-1.48)$ & $0.95(0.71-1.28)$ & $1.04(0.75-1.43)$ & $1.06(0.83-1.34)$ \\
\hline $\mathrm{NO}_{2}$ & $1.03(0.80-1.34)$ & NA & $1.17(0.86-1.60)$ & $0.90(0.65-1.25)$ & $0.98(0.70-1.39)$ & $1.04(0.79-1.35)$ \\
\hline
\end{tabular}

Data are presented as ${ }^{\#}$ adjusted odds ratio of symptoms ( $95 \%$ confidence intervals) associated with a change in concentration of $1.5 \mu \mathrm{g} \cdot \mathrm{m}^{-3}$ for $\mathrm{PM} 2.5,0.4 \times 10^{-5} \cdot \mathrm{m}^{-1}$ for $\mathrm{PM} 2.5$ abs and $8.5 \mu \mathrm{g} \cdot \mathrm{m}^{-3}$ for $\mathrm{NO}_{2}$. PM 2.5 : particles with a $50 \%$ aerodynamic diameter of $2.5 \mu \mathrm{m} ; \mathrm{NO}_{2}$ : nitrogen dioxide; obstr.: obstructive; spast.: spastic; NA: not available. ${ }^{\#}$ : Adjusted for parental atopy (yes/no), maternal education, siblings $(y / n)$, environmental tobacco smoke at home $(y / n)$, use of gas for cooking (y/n), home dampness $(y / n)$, indoor moulds $(y / n)$, keeping of dogs $(y / n)$ and cats $(y / n)$ study (German Infant Nutrition Intervention Programme (GINI)-intervention, GINI-observation, Lifestyle Related Factors on the Human Immune System and Development of Allergies in Asthma (LISA)).

such as upper respiratory symptoms [18], cough symptoms $[4,8,16,25,26]$, wheeze $[3,6,8,9,11$, $12,25]$, bronchitic symptoms [12], bronchitis [4, 16, $26]$, asthma [8, 10, 25, 27], runny nose [8], and allergic rhinitis [11, 13], medical care visits for asthma [14] and decreased lung function $[6,9,17,28]$. Only a few studies, assessing the relationship between $\mathrm{NO}_{2}$ and particle concentrations and respiratory symptoms and illnesses in infants, were found in literature. These studies did not provide unequivocal evidence of air pollution effects. BRAUN-FAHRLANDER and co-workers $[5,29]$ analysed associations between outdoor $\mathrm{NO}_{2}$ concentrations and respiratory symptoms in Swiss children aged 0-5 yrs. They found the frequency of respiratory symptoms per child per day [27] as well as the duration of respiratory symptoms [5] increased with increasing levels of $\mathrm{NO}_{2}$. Furthermore, they found an association between particle concentrations and incidence and duration of respiratory symptoms [5]. Pershagen et al. [30] found $\mathrm{NO}_{2}$ concentrations estimated from validated dispersion models related to incidence rates of wheezing bronchitis in females aged 4 months -4 yrs $(90 \%$ of the children were $<2 \mathrm{yrs})$. In another study conducted by MAGNUs et al. [31], an association between bronchial obstruction in children aged $0-5$ yrs and $\mathrm{NO}_{2}$ levels measured inside and outside the childrens' homes as well as the distance of the child's home to the nearest street, could not be shown. SAMET et al. [32] analysed the relationship between indoor $\mathrm{NO}_{2}$ and incidence rate of upper and lower respiratory illness in infants aged $0-18$ months and no association could be shown. The same was true for FARRow et al. [33] who failed to show an association between symptoms and concentrations of $\mathrm{NO}_{2}$ measured inside the bedrooms and outside the homes of infants aged 3-12 months. In these indoor studies, however, $\mathrm{NO}_{2}$ represents emissions from unvented gas stoves, which may have a very different composition than traffic exhaust.

Results for cough were not presented separately for the studies dealing with infants, but they were for some of the studies dealing with schoolchildren. Five studies showed a significant association between symptoms of cough and traffic-related air pollution $[4,8,16,25,26]$. The effects for wheeze reported for several other studies, as well as the effects for bronchitis, could not be confirmed by the present study, but reports of wheeze in children aged 1 or 2 yrs probably represent different disease patterns than reports of wheeze in school children. The prevalence of asthma was not sufficient to allow an analysis of the relationship with traffic-related air pollution.

Associations between exposure to traffic-related air pollutants and parameters of respiratory health for the Dutch and the Swedish centres will be published in separate papers. Analyses of the respiratory symptom data of the Dutch part of the TRAPCA study have shown an association between exposure to trafficrelated air pollution and wheeze and asthma in the first 2 yrs of life. The significant association between cough and air pollution in the German cohort could not be confirmed. In Sweden there was a nonsignificant positive association between asthma at the age of 2 yrs (the only end point analysed) and air pollution. Since the diagnosis of specific respiratory illnesses during the first years of life is difficult, a more definitive conclusion about the risk of traffic-related air pollution on respiratory health and in particular on asthma requires further studies when the children are older.

Only a few studies have reported stratified analyses by sex. VAN Vliet et al. [8], BruneKreef et al. [17], and Pershagen et al. [30] found stronger effects for 
females compared to males. This disagrees with the results in this study of stronger effects in males compared to females. Pershagen et al. [30] argued that air pollution effects might be more difficult to detect in cases where very young males have a higher incidence of symptoms than females. In accordance with Pershagen et al. [30], higher incidences of respiratory symptoms in males compared to females were also found in the present study (data not shown). This is also consistent with a retrospective analysis of the data of the European Respiratory Health Survey [34] which showed that males aged 0-5 yrs have a significantly higher risk of developing asthma than females. It has been shown that females aged 0-2 yrs have larger airways in relation to lung size than males [35], and that specific airway resistance is lower at any given height in female then in male infants of this age group [36]. These differences in lung growth and development between males and females might be responsible for the higher incidences of symptoms and the greater susceptibility of males, resulting in higher effects of air pollution in males compared to females. However, separate analyses for males and femalea are available for a very limited number of studies and the differences are still not completely understood.

There was a high correlation found between estimated concentrations of PM2.5, PM2.5 absorbance, and $\mathrm{NO}_{2}$ and therefore similar associations with health outcomes for the three pollutants. Thus, it was impossible to distinguish potential health effects of emissions from all motorized vehicles from those of heavy vehicles only.

The effects of traffic-related air pollutants on symptoms of cough were attenuated for the second year of life. The meaning of this finding is not quite clear. It could be due to the fact that 454 infants moved within the second year of life hence introducing some "noise". But results of additional analyses without those children (for whom estimated exposures at their birth address does not represent lifetime exposure) differed only marginally from those presented in table 3 (data not shown). Furthermore, one might speculate that the associations between trafficrelated air pollution at birth addresses and symptoms of cough were attenuated as a result of an increased mobility of the children in the second year of life e.g. due to day-care attendance. Further analyses when the children are older will have to show whether the effects observed in the present study are transient or whether traffic-related air pollutants have nontransient effects on the development of inhalant allergy, asthma and other chronic respiratory conditions in children.

The aim of the present study was to analyse the health effects associated with long-term exposure to traffic-related air pollutants. It is generally agreed to refer to studies designed as the TRAPCA study, as studies on long-term exposure of air pollution. In fact, the study was not designed in a way that allowed for the disentanglement long-term effects from shortterm effects. The observed effects of annual average concentrations of traffic-related air pollutants on life time prevalence of symptoms of cough might also result from short-term exposure, that is exposure just before onset of symptoms, given that a location with a higher annual average concentration is also more likely to have higher peaks in daily average concentrations in the course of the 1-yr period of interest. Since both, exposure and health data, were collected on an annual basis and not on a daily basis, it is impossible, by the design of the study, to distinguish between long-term and short-term effects. However, study designs, like that of the present study, are referred to as long-term study designs, although they include both, long-term and short-term effects. In contrast to this, studies on short-term effects relating day-to-day variation in air pollution concentration to day-to-day variation in health outcomes have a completely different study design.

Reporting bias is possible when there is increased awareness of exposure in parents of symptomatic children. However, the underlying cohort studies have been primarily designed to analyse the effects of nutrition and lifestyle-related factors on the development of atopic disease and the immune system. Thus, the parents were not aware of the hypothesis of the present study. Furthermore, parents were unaware of the estimated exposures to air pollutants. Therefore, it seems unlikely that the relationship between trafficrelated air pollution and symptoms of cough may have been caused by over-reporting of symptoms by parents exposed to high levels of air pollution.

A large set of confounding variables was taken into account in this study, and all results presented were adjusted for these variables. After adjustment for sex parental atopy, maternal education, siblings, ETS at home, use of gas for cooking, home dampness, indoor moulds and the keeping of dogs and cats the associations of symptoms of cough with traffic-related air pollution remained.

To conclude, there is some indication of an association between exposure to traffic-related air pollution and symptoms of cough. Associations were stronger in males than in females. Due to the very young age of the children, it is too early to draw definitive conclusions from this for the development of asthma. Thus, the association between long-term exposure to traffic-related air pollution and respiratory symptoms needs further study when the children are older.

Acknowledgements. The authors would like to thank all members of the GINI and the LISA study groups and all families for their participation.

\section{References}

1. Kunzli N, Kaiser R, Medina S, et al. Public health impact of outdoor and traffic-related air pollution: a European assessment. Lancet 2000; 356: 795-801.

2. Kunzli N, Tager IB. Long-term health effects of particulate and other ambient air pollution: research can progress faster if we want it to. Environ Health Perspect 2000; 108: 915-918. 
3. Oosterlee A, Drijver M, Lebret E, Brunekreef B. Chronic respiratory symptoms in children and adults living along streets with high traffic density. Occup Environ Med 1996; 53: 241-247.

4. Hirsch T, Weiland SK, von Mutius E, et al. Inner city air pollution and respiratory health and atopy in children. Eur Respir J 1999; 14: 669-677.

5. Braun-Fahrlander C, Ackermann-Liebrich U, Schwartz J, Gnehm HP, Rutishauser M, Wanner HU. Air pollution and respiratory symptoms in preschool children. Am Rev Respir Dis 1992; 145: 42-47.

6. Roemer W, Hoek G, Brunekreef B. Effect of ambient winter air pollution on respiratory health of children with chronic respiratory symptoms. Am Rev Respir Dis 1993; 147: 118-124.

7. Nitta H, Sato T, Nakai S, Maeda K, Aoki S, Ono M. Respiratory health associated with exposure to automobile exhaust. Results of cross-sectional studies in 1979, 1982, and 1983. Arch Environ Health 1993; 48: 53-58.

8. van Vliet $\mathrm{P}$, Knape $\mathrm{M}$, de Hartog J, Janssen N, Harssema H, Brunekreef B. Motor vehicle exhaust and chronic respiratory symptoms in children living near freeways. Environ Res 1997; 74: 122-132.

9. Wjst M, Reitmeir P, Dold S, et al. Road traffic and adverse effects on respiratory health in children. $B M J$ 1993; 307: 596-600.

10. Duhme H, Weiland SK, Rudolph $\mathrm{P}$, Wienke A, Kramer A, Keil U. Asthma and allergies among children in West and East Germany: a comparison between Munster and Greifswald using the ISAAC phase I protocol. International Study of Asthma and Allergies in Childhood. Eur Respir J 1998; 11: 840 847.

11. Duhme H, Weiland SK, Keil U, et al. The association between self-reported symptoms of asthma and allergic rhinitis and self-reported traffic density on street of residence in adolescents. Epidemiology 1996; 7: $578-82$.

12. Ciccone G, Forastiere F, Agabiti N, et al. Road traffic and adverse respiratory effects in children. SIDRIA Collaborative Group. Occup Environ Med 1998; 55: 771-778.

13. Weiland SK, Mundt KA, Ruckmann A, Keil U. Selfreported wheezing and allergic rhinitis in children and traffic density on street of residence. Ann Epidemiol 1994; 4: 243-247.

14. English P, Neutra R, Scalf R, Sullivan M, Waller L, Zhu L. Examining associations between childhood asthma and traffic flow using a geographic information system. Environ Health Perspect 1999; 107: 761767.

15. Wilkinson $\mathrm{P}$, Elliott $\mathrm{P}$, Grundy $\mathrm{C}$, et al. Case-control study of hospital admission with asthma in children aged 5-14 years: relation with road traffic in north west London. Thorax 1999; 54: 1070-1074.

16. Dockery DW, Speizer FE, Stram DO, Ware JH, Spengler JD, Ferris BG Jr. Effects of inhalable particles on respiratory health of children. Am Rev Respir Dis 1989; 139: 587-594.

17. Brunekreef B, Janssen NA, de Hartog J, Harssema H, Knape M, van Vliet P. Air pollution from truck traffic and lung function in children living near motorways. Epidemiology 1997; 8: 298-303.

18. von Mutius E, Sherrill DL, Fritzsch C, Martinez FD, Lebowitz MD. Air pollution and upper respiratory symptoms in children from East Germany. Eur Respir $J$ 1995; 8: 723-728.

19. Briggs D, Collins S, Elliott $\mathrm{P}$, et al. Mapping urban air pollution using GIS: a regression-based approach. Int J Geographical Information Science 1997; 11: 699718.

20. Briggs DJ, de Hoogh C, Gulliver J, et al. A regressionbased method for mapping traffic-related air pollution: application and testing in four contrasting urban environments. Sci Total Environ 2000; 253: 151-167.

21. Statisches Amt der Landeshauptstadt Muenchen. Basisdaten: Jaherszahen aus den verschiedensten Berichten der Kommunalstatistik. München. http:// www.muenchen.de/statmt/index.html.

22. Marple VA, Rubow KL, Turner W, Spengler JD. Low Flow Rate Sharp Cut Impactor for Indoor Air Sampling: Design and Calibration. $J$ Air Pollut Control Assoc 1987; 37: 1303-1307.

23. Fischer $\mathrm{PH}$, Hoek $\mathrm{G}$, van Reeuwijk $\mathrm{H}$, et al. Traffic-related differences in outdoor and indoor concentrations of particles and volatile organic compounds in Amsterdam. Atmos Environ 2000; 34: 37133722.

24. Institute for Risk Assessment Sciences at Utrecht University. Risk assessment of exposure to trafficrelated air pollution for the development of inhalant allergy, asthma and other chrionic respiratory conditions in children (TRAPCA), EU Grant ENV4CT97-0506. Final report. Utrecht, the Netherlands, University of Utrecht.

25. Studnicka M, Hackl E, Pischinger J, et al. Trafficrelated $\mathrm{NO} 2$ and the prevalence of asthma and respiratory symptoms in seven year olds. Eur Respir $J$ 1997; 10: 2275-2278.

26. Braun-Fahrlander C, Vuille JC, Sennhauser FH, et al. Respiratory health and long-term exposure to air pollutants in Swiss schoolchildren. SCARPOL Team. Swiss Study on Childhood Allergy and Respiratory Symptoms with Respect to Air Pollution, Climate and Pollen. Am J Respir Crit Care Med 1997; 155: 1042-1049.

27. Guo YL, Lin YC, Sung FC, et al. Climate, trafficrelated air pollutants, and asthma prevalence in middle-school children in taiwan. Environ Health Perspect 1999; 107: 1001-1006.

28. Beyer U, Franke K, Cyrys J, et al. Air pollution and respiratory health of children: the PEACE panel study in Hettstedt and Zerbst, Eastern Germany. Eur Resp Rev 1998; 8: 61-69.

29. Braun-Fahrlander C, Ackermann-Liebrich U, Wanner HU, Rutishauser M, Gnehm HE, Minder CE. Effects of air pollutants on the respiratory system in young children. Schweiz Med Wochenschr 1989; 119: 1424 1433.

30. Pershagen G, Rylander E, Norberg S, Eriksson M, Nordvall SL. Air pollution involving nitrogen dioxide exposure and wheezing bronchitis in children. Int J Epidemiol 1995; 24: 1147-1153.

31. Magnus $\mathrm{P}, \mathrm{Nafstad} \mathrm{P}$, Oie L, et al. Exposure to nitrogen dioxide and the occurrence of bronchial obstruction in children below 2 years. Int $J$ Epidemiol 1998; 27: 995-999.

32. Samet JM, Lambert WE, Skipper BJ, et al. Nitro gen dioxide and respiratory illness in children. Part I: Health outcomes. Res Rep Health Eff Inst 1993; $1-32$. 
33. Farrow A, Greenwood R, Preece S, Golding J. Nitrogen Dioxide, the oxides of nitrogen and infants' health symptoms. Arch Environ Health 1997; 52: 189194.

34. de Marco R, Locatelli F, Sunyer J, Burney P. Differences in incidence of reported asthma related to age in men and women. A retrospective analysis of the data of the European Respiratory Health
Survey. Am J Respir Crit Care Med 2000; 162: 6874.

35. Thurlbeck WM. Postnatal human lung growth. Thorax 1982; 37: 564-71.

36. Doershuk CF, Fisher BJ, Matthews LW. Specific airway resistance from the perinatal period into adulthood. Alterations in childhood pulmonary disease. Am Rev Respir Dis 1974; 109: 452-7. 